\title{
IUFOST2006/409 \\ An Interdisciplinary Approach to Improving Sea Urchin Roe and Developing a High Value Export Market
}

\author{
P. Silcock ${ }^{\mathrm{a}}$, S. Then ${ }^{\mathrm{a}}$, C. Delahunty ${ }^{\mathrm{a}}$, M. Barker ${ }^{\mathrm{a}}$, R. Law ${ }^{\mathrm{a}}$, M. Sewell ${ }^{\mathrm{b}}$, S. Bishop $^{\mathrm{b}}$ and P. Bremer ${ }^{\mathrm{a}}$ \\ ${ }^{a}$ University of Otago, Department of Food Science, PO Box 56, 9001 Dunedin, New Zealand \\ ${ }^{\mathrm{b}}$ Auckland University, Private Bag 92019, 1020 Auckland, New Zealand \\ pat.silcock@stonebow.otago.ac.nz
}

Sea urchin roe is considered to be a delicacy in many countries. The Japanese are the main consumers of sea urchin roe (known as uni) and Japan imports around 6,000 metric tons of roe annually where it currently commands prices of up to \$US300kg-1. Though New Zealand have huge stocks of sea urchin (Evechinus chloroticus; local name Kina), previous attempts to export this product to Japan have failed as the wildcaught fishery does not consistently produce roe with desirable qualities (sweet taste and yellow/orange colour). Until now the underlying causes of the variability have not been investigated resulting in an ad-hoc approach to market development.

Our approach has been to form a multidisciplinary team consisting of food chemists, sensory scientists and marine biologists to characterise the effect of urchin size, sex and diet on roe yield, composition, sensory properties and colour. After being fed a controlled diet the physical properties of the urchins were measured and the roes analysed by sensory descriptive analysis and compositional analysis, including moisture, soluble protein, glycogen, lipid, free amino acids, ATP and related ATP products.

The compositional analysis of the roe confirmed that a large variation existed between individual urchins. For example, the soluble protein content of the roe varied from $8.1 \%$ to $0.8 \% \mathrm{w} / \mathrm{w}$ wet basis. The free amino acid profile of the urchin roe was dominated by glycine, which comprised more than $50 \%$ of the free amino acids present. Glutamic acid, alanine, methionine, valine, leucine and tyrosine while being present in variable amounts appear to contribute to the flavour of the roe. The colour results suggested that poor colour was associated with urchin size/age. As urchin diameter increased above $100 \mathrm{~mm}$ diameter brown coloured roe became increasing predominant. Bitterness was found to be associated with female roes and may be associated with the reproductive cycle. A link between an odour compound or compounds and bitterness is being evaluated. The establishment of a link may enable key a quality parameter to be predicted without the need for frequent destructive sampling of roe. This will be an important step towards the ability to supply a consistent product. The next stage is to use ranching, harvesting and processing strategies to mitigate or control the perceived variability in roe quality. The ability to provide kina roe of a consistently high quality will underpin the development of a high value export market for New Zealand sea urchin roe. 